\title{
Can maternal serum C-reactive protein levels predict successful labour induction with intravenous oxytocin in term pregnancies complicated with premature rupture of the membranes? A cross-sectional study
}

\author{
Serkan Kahyaoğlu ${ }^{1}$, Hakan Timur ${ }^{1}$, Remzi Eren², İnci Kahyaoğlư ${ }^{3}$ Elif Gül Yapar Eyi ${ }^{1}$, Yaprak Engin-Üstün ${ }^{4}$ \\ 'Department of Obstetrics and Gynecology, Dr. Zekai Tahir Burak Women's Health Education and Research Hospital, \\ Ankara, Turkey \\ ${ }^{2}$ Department of Obstetrics and Gynecology, Sakarya Maternity Hospital, Sakarya, Turkey \\ ${ }^{3}$ Department of Obstetrics and Gynecology, Etlik Zübeyde Hanım Women's Health Education and Research Hospital, \\ Ankara, Turkey \\ ${ }^{4}$ Department of Obstetrics and Gynecology, Bozok University Faculty of Medicine, Yozgat, Turkey
}

\section{Abstract}

Objective: High sensitive C-reactive protein (hs-CRP) is a serum marker for acute inflammation and/ or infection. The diagnostic value of serum levels of this protein has been investigated among patients with preterm delivery, premature rupture of the membranes (PROM) and preeclampsia. In this study, the predictive value of hs-CRP for successful labour induction in patients with PROM has been evaluated.

Material and Methods: Eighty-six term pregnant patients who experienced pre-labour amniotic membrane rupture from 37-41 weeks of gestation were selected for the study. Maternal serum hs-CRP levels were determined upon admission to the delivery unit and low dose intravenous oxytocin infusion was started to induce labour. The mode of delivery and time interval from labour induction to delivery were the primary endpoints of the study.

Results: Twenty-five (29\%) out of 86 patients had delivered by caesarean section, while the remaining 61 (71\%) had delivered vaginally. The receiver operator characteristic (ROC) curve for testing the significance of higher hs-CRP values and lower probability of vaginal delivery revealed that higher hs-CRP values were found to be insignificant for predicting the need for caesarean section. No statistically significant correlation between high serum hs-CRP levels and the probability of caesarean delivery has been established (Spearman rho:-.126; $p=0.24$ ). The mean maternal serum hs-CRP levels during PROM were found to be similar between vaginal and abdominal deliveries.

Conclusion: Hs-CRP, as an inflammatory marker, was found to be neither specific nor sensitive for the prediction of successful labour induction in term pregnancies with pre-labour rupture of the membranes. (J Turk Ger Gynecol Assoc 2014; 15: 36-40)

Key words: C-reactive protein, premature rupture of the membranes, labour induction

Received: 03 August, 2013

Accepted: 11 October, 2013

\section{Introduction}

High sensitive C-reactive protein (hs-CRP) is an acute phase reactant protein that is secreted to the circulation from the liver as a reaction to the onset of inflammation and/or acute tissue injury. Maternal serum hs-CRP measurement was assumed to be a clinical indicator for women with preterm labour or preterm rupture of membranes related to the possible preceding subclinical maternal infection. Watts et al. (1) determined hs-CRP levels serially from 22 weeks' gestation until delivery in healthy pregnant women without antepartum complications; the median hs-CRP values ranged from 0.7-0.9 $\mathrm{mg} / \mathrm{dL}$ for women who were not in labour and showed no significant change in serum levels of hs-CRP according to the gestational age. Kashanian et al. (2) evaluated the diagnostic value of maternal serum hs-CRP measurement during the first trimester of pregnancy for predicting pre-eclampsia. A systematic review conducted by Rebelo et al. (3) also suggested that women with higher levels of hs-CRP may have an increased risk of developing preeclampsia. Measurement of the first trimester maternal serum hs-CRP levels for the prediction of subsequent preterm delivery was found to be use- 
less (4). Unexpectedly, Moghaddam et al. (5) found a significant relationship between elevated maternal serum hs-CRP levels in the first 20 weeks of pregnancy and the later occurrence of preterm premature rupture of membranes (PPROM) and preterm birth, with a cut-off level of hs-CRP level $>4 \mathrm{mg} / \mathrm{L} \mathrm{dem-}$ onstrating statistically significant relationships with PPROM and preterm birth. Although the hs-CRP values seem to be higher than expected for non-pregnant women, hs-CRP values physiologically increased during labour (6). However, hs-CRP levels increased following both vaginal and caesarean deliveries; the exact interval between the elevation of hs-CRP and the onset of labour at term is not known. A possible association between high hs-CRP levels in maternal serum early in pregnancy have also been described as a marker of preterm delivery, intrauterine infection and PPROM (7). The relationship between maternal serum hs-CRP levels during admission to the delivery unit and successful labour induction with i.v. oxytocin in patients with pre-labour PROM has not been hugely studied before. In this study, we tried to evaluate the relationship between serum hs-CRP levels of term pregnant women who have experienced pre-labour amniotic membrane rupture and successful labour induction with a low dose oxytocin infusion. Our aim was to determine a cut-off value for hs-CRP levels that predicts the low probability of achieving vaginal delivery.

\section{Material and Methods}

This cross-sectional study was conducted at the delivery ward of a tertiary education and research hospital with a delivery rate of approximately 20,000/year between January 2011 and June 2011. This study was approved by the Ethical Committee of the hospital and informed consent was taken from the patients before the study began. During this time period, 572 term pregnant patients who experienced pre-labour amniotic membrane rupture from 37-41 weeks of gestation were evaluated and 86 eligible women were selected for the study. Patients with a Bishop score $\geq 5$, a non-vertex presentation, cephalopelvic disproportion, macrosomia, uterine contractions on non-stress test, active labour with cervical dilatation more than 3 centimetres upon admission, systemic illness, gestational hypertension, gestational diabetes and patients who had not undergone labour for other obstetric indications were excluded from the study. All patients received prophylactic antibiotics (1 g of i.v. cephazoline 12 hours apart) from admission to delivery. Hs-CRP was measured with a high sensitivity immunoturbidimetric assay (Roche Diagnostics, Indianapolis, IN, USA) using an automated clinical chemistry analyser. The hs-CRP assay coefficients of variation were $2.7 \%$ at $0.12 \mathrm{mg} / \mathrm{L}, 3.45 \%$ at 0.41 $\mathrm{mg} / \mathrm{L}$, and $5.7 \%$ at $0.03 \mathrm{mg} / \mathrm{L}$. The assay had a detection limit of $0.03 \mathrm{mg} / \mathrm{L}$ and a calibration range of up to $300 \mathrm{mg} / \mathrm{L}$. The normal range reference interval of hs-CRP for adults was accepted as $<5 \mathrm{mg} / \mathrm{L}$. Blood samples for the determination of hs-CRP levels of patients were drawn only once immediately upon admission to the ward.

Then, low dose intravenous oxytocin infusion, prepared as a $500 \mathrm{~mL}$ isotonic fluid including 5 IU oxytocin, was started with different time intervals following the membrane rupture to induce labour. Dose increments were made every 15 minutes starting with $12 \mathrm{~mL} /$ hour until satisfactory uterine contractions (3 contractions/10 minutes) were achieved. The progression of labour of the 86 recruited patients was followed until delivery by physicians who were blinded about the study. The primary endpoints of the study were the mode of delivery and time interval from labour induction to vaginal delivery. All statistical analyses were performed using IBM SPSS Statistics Software (19.0, SPSS Inc., Chicago, IL, USA). Data were assessed for normality using the Kolmogorov-Smirnov test. The continuous variables were presented by means \pm standard deviation (SD) and compared using the independent samples $t$ test. The nonparametric variables and data without normality were tested using the Mann Whitney U test. The comparison of categorical values was accomplished by using Fisher's exact test or the chi-square test. $P$ values $<0.05$ were considered statistically significant. The Receiver Operating Characteristic (ROC) analysis was used to estimate an optimal threshold score of hs-CRP to predict successful labour progress. The spearman correlation test was used for evaluation of the correlation between variables of which variances were not equally assumed.

\section{Results}

The clinical characteristics of the total study group are presented in Table $1(\mathrm{~N}=86)$. The majority of the participants were nullipar (72.1\%) and $60.5 \%$ of them had a low socioeconomic status. Twenty-five (29\%) out of the 86 patients had delivered by caesarean section, while the remaining 61 (71\%) delivered vaginally. The caesarean section indications were unsuccessful labour induction (60\%), cephalopelvic disproportion (24\%) and foetal distress (16\%) $(\mathrm{N}=25)$. Among all patients, $15(17 \%)$ underwent caesarean section due to unsuccessful labour induction. When the cases were categorised according to the delivery mode, no significant differences were found between the vaginally and abdominally delivered patients regarding the mean levels of age, gestational age at admission, body mass index, hs-CRP, lactate dehydrogenase (LDH), neutrophil count percent, white blood cells count, birth-weight and the time interval between PROM and the induction of labour $(p>0.05)$ (Table 2). The mean cervical length measurement (millimetres) of the vaginally delivered patients at admission was significantly lower than abdominally delivered patients $(26 \pm 7$ versus $32 \pm 4$ respectively; $p=0.01$ ). The mean time intervals between labour induction and delivery (hours) of the vaginally and abdominally delivered patients were $8.2 \pm 6.9$ and $12 \pm 6.7$ hours, respectively $(p=0.016)$. The receiver operator characteristic (ROC) curve for testing the significance of higher hs-CRP values and higher probability of caesarean delivery revealed that higher hs-CRP values had at least one insignificant relation with a higher caesarean section rate (Area under curve (AUC):0.57; $\mathrm{p}=0.22$ ) (Figure 1). A significant relationship between higher cervical length at admission and lower probability of vaginal delivery was established $(\mathrm{AUC}=0.71 ; \mathrm{p}=0.001,95 \% \mathrm{CI}=0.61$ 0.82 ) ( $80 \%$ sensitivity and $58 \%$ specificity for a cut-off value $27.5 \mathrm{~mm}$ ) (Figure 2). The ROC curve analysis of the increasing time interval elapsed from premature membrane rupture to 
Table 1 . The clinical characteristics of the study group $(\mathrm{N}=86)$ *

\begin{tabular}{|l|c|c|c|c|c|}
\hline & N & Minimum & Maximum & Mean & Std. Deviation \\
\hline Age (years) & 86 & 18 & 40 & 26 & 5 \\
\hline $\begin{array}{l}\text { Gestational week } \\
\text { at admission to the ward }\end{array}$ & 86 & 37 & 41 & 38 & 1 \\
\hline BMI (kg/m²) & 86 & 22 & 38 & 28 & 3 \\
\hline CRP (mg/dL) & 86 & 0.4 & 44 & 9.5 & 11.1 \\
\hline LDH (IU) & 86 & 206 & 576 & 341 & 75 \\
\hline Haemoglobin (mg/dL) & 86 & 9.1 & 14.7 & 11.8 & 1.2 \\
\hline WBC (number/mm $\left.{ }^{3}\right)$ & 86 & 5840 & 21000 & 11497 & 7 \\
\hline Neutrophil count (percent) & 86 & 58 & 90 & 74 & 7 \\
\hline Cervical length (mm) & 86 & 6 & 41 & 28 & 391 \\
\hline Birth-weight (grams) & 86 & 2530 & 4280 & 3142 & \\
\hline $\begin{array}{l}*: \text { Whole study group } \\
\text { BMI: Body mass index; CRP: C-reactive protein; LDH: Lactate dehydrogenase; WBC: White blood cell }\end{array}$ & & \\
\hline
\end{tabular}

Table 2. The clinical characteristics of the study group $(\mathrm{N}=86)^{*}$

\begin{tabular}{|l|c|c|c|}
\hline Parameter & $\begin{array}{c}\text { Vaginal } \\
\text { Delivery } \\
\text { (N=61) }\end{array}$ & $\begin{array}{c}\text { Abdominal } \\
\text { Delivery } \\
\text { (N=25) }\end{array}$ & p value \\
\hline Age (years) & $25.7 \pm 5.2$ & $27.8 \pm 5.8$ & $0.08^{* *}$ \\
\hline Gestational week at admission to the ward & $38 \pm 1$ & $39 \pm 1$ & $0.28^{* *}$ \\
\hline BMI (kg/m $\left.{ }^{2}\right)$ & $27.7 \pm 3.2$ & $29.1 \pm 3.5$ & $0.06^{* *}$ \\
\hline CRP (mg/dL) & $8.1 \pm 9.2$ & $11.6 \pm 13.2$ & $0.22^{*}$ \\
\hline LDH (IU) & $352 \pm 78$ & $325 \pm 70$ & $0.10^{* *}$ \\
\hline Neutrophil count (percent) & $75 \pm 8$ & $73 \pm 5$ & $0.21^{*}$ \\
\hline WBC (number/mm $)$ & $11690 \pm 3334$ & $11215 \pm 1818$ & $0.63^{*}$ \\
\hline Cervical length (mm) & $26 \pm 7$ & $32 \pm 4$ & $0.01^{*}$ \\
\hline Birth-weight (grams) & $3150 \pm 160$ & $3191 \pm 156$ & $0.16^{* *}$ \\
\hline $\begin{array}{l}\text { Time interval between premature membrane rupture and labour } \\
\text { induction (hours) }\end{array}$ & $7.6 \pm 4.5$ & $9.3 \pm 5.3$ & $0.10^{* *}$ \\
\hline Time interval between labour induction and delivery (hours) & $8.2 \pm 6.9$ & $12 \pm 6.7$ & $0.016^{* * *}$ \\
\hline $\begin{array}{l}*=p \text { value (Mann-Whitney U test) } \\
* * \text { *: value (Independent Samples t test) } \\
\text { BMI: Body mass index; CRP: C-reactive protein; LDH: Lactate dehydrogenase; WBC: White blood cell }\end{array}$ & & \\
\hline
\end{tabular}

labour induction (hours) and delivery revealed a positive but insignificant relationship with higher abdominal delivery rate (AUC $=0.59 ; \mathrm{p}=0.14$ ). When we tested the possible correlation between high serum hs-CRP levels and the probability of caesarean delivery, we could not establish any significant correlation (Spearman rho: $-.126 ; \mathrm{p}=0.24$ ).

\section{Discussion}

In this study, we evaluated the relationship between serum hs-CRP levels and the mode of delivery among patients with PROM who received labour induction with low dose i.v. oxytocin. Although hs-CRP levels increase during active labour, the clinical value of this acute phase reactant had not been previously studied in detail for patients with membrane rupture preceding uterine contractions. Whether an increased hs-CRP level represents a subclinical intrauterine infection without any microbiological confirmative test that precludes efficient uterine contractions to proceed labour or not has been evaluated. Previous studies demonstrated a relationship between high serum hs-CRP levels and PROM (8). Before encountering the clinical scene of the preterm labour caused by certain intrauterine infections, hs-CRP levels can be found to be high in the serum earlier during the course of the preterm labour pathophysiology. In two systematic reviews, conducted by Van de Laar et al. (9) and Trochez-Martinez et al. (10), the predictive value of maternal serum hs-CRP for clinical chorioamnionitis and/or neonatal sepsis in women with PPROM was evaluated. 


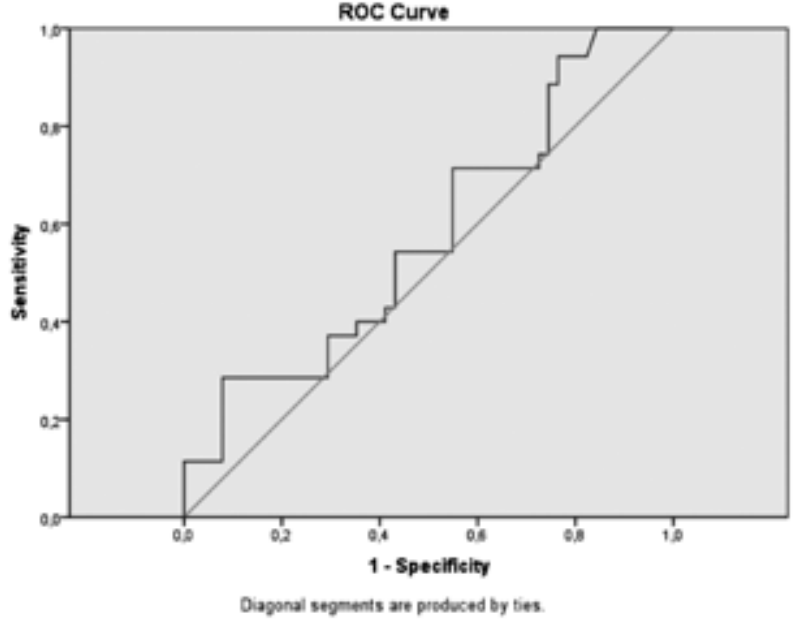

Figure 1. The ROC curve demonstrating the direct proportional relationship between the higher $C R P$ values and the higher probability of caesarean section $(\mathrm{AUC}=0.57 ; \mathrm{p}=0.22,95 \% \mathrm{CI}=0.45$ 0.70) $(\mathrm{N}=86)$

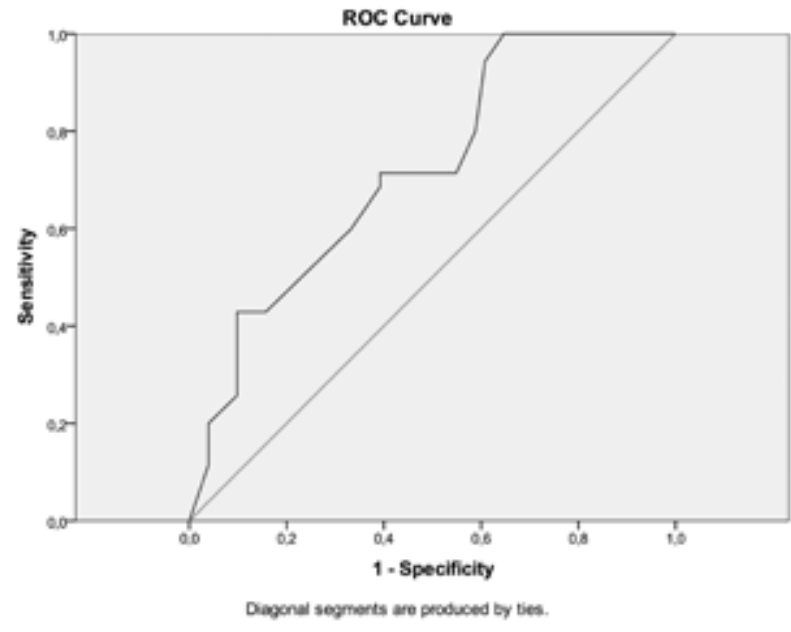

Figure 2. The ROC curve demonstrating the direct proportional relationship between the higher cervical length and lower probability of vaginal delivery $(\mathrm{AUC}=0.71 ; \mathrm{p}=0.001,95 \% \mathrm{CI}=0.61-0.82)$ $(\mathrm{N}=86)$

The current data were not sufficient to suggest the use of hsCRP in women with PPROM. The foetal immune system also has the ability to produce hs-CRP into the amniotic fluid as a response to subclinical intrauterine infection. In a prospective study, amniotic fluid hs-CRP measurements were studied during mid-trimester amniocentesis for genetic indications and levels $>0.65 \mathrm{mg} / \mathrm{L}$ were found to be related to increased preterm delivery risk (11). Ghezzi et al. (12) evaluated pre-existing intrauterine inflammation by measuring amniotic fluid hs-CRP levels in the first half of gestation as a possible condition that leads to preterm delivery; they found that an amniotic fluid hsCRP concentration of $>110 \mathrm{ng} / \mathrm{mL}$ had a sensitivity of $80.8 \%$ and a specificity of $69.5 \%$ in the prediction of spontaneous preterm delivery at $<34$ weeks, revealing that subclinical intrauterine/ foetal inflammatory processes early in gestation may be a cause of preterm delivery in the second half of gestation. Oh et al. (13) evaluated the predictive value of intra-amniotic matrix metalloproteinase 9 (MMP-9), interleukin 6 (IL-6) levels and maternal serum hs-CRP for histologic chorioamnionitis and intra-amniotic infection among patients with preterm labour or preterm PROM (21-35 weeks of gestation) who delivered within 72 hours of transabdominal amniocentesis. The amniotic fluid (AF) MMP-9 was found to be a better diagnostic marker than AF IL-6 and maternal serum hs-CRP in predicting intra-amniotic infection. Interestingly, in the same study, the serum hs-CRP levels obtained up to 72 hours before delivery were found to be valuable for the early identification of histologic chorioamnionitis in women without an intra-amniotic infection.

In this study, a significant relationship between higher cervical length at admission and lower probability of vaginal delivery was established for patients with PROM. Greater cervical length of the patients with PROM at admission seemed to preclude successful labour induction with oxytocin. We could not establish any relationship between the serum hs-CRP levels and the mode of delivery. Hs-CRP levels of patients with PROM did not have any predictive value for successful labour induction following the rupture of the membranes. It is possible that subclinical intrauterine infection with high serum hs-CRP levels exerts little effect on the uterine contractility, which precludes any significant change in the mode of the delivery. Before the initiation of uterine contractions following the PROM event, the mechanism that increases the hs-CRP values to the levels that are consistent with active labour might already have been established. The rapid initiation of prophylactic antibiotics to the patients also might have lowered the negative effects of the subclinical intrauterine infection to the uterine contractility. Randomised controlled studies conducted among patients with PROM are needed to evaluate the predictive value of serum hs-CRP and/or other systemic inflammatory markers for successful labour induction. However, the higher serum hs-CRP levels have been detected among postdate ( $>40$ gestational weeks) women whose labour will start with PROM than in women whose labour starts otherwise; the clinical utilisation of this fact is lacking (8). When a PROM patient is admitted to the delivery unit, it is wise to evaluate a possible subclinical intrauterine infection with confirmative microbiological tests of the amniotic fluid rather than serum hs-CRP levels. Administration of prophylactic antibiotics immediately upon admission to the ward is another realistic option for these patients because the microbiological culture results will probably not be available as quickly. The prediction of successful labour induction among patients with PROM using serum hs-CRP levels does not have promising results for the routine recommendation of this test to all patients with PROM.

Ethics Committee Approval: Ethics committee approval was received for this study.

Informed Consent: Written informed consent was obtained from patients who participated in this study. 


\section{Peer-review: Externally peer-reviewed.}

Author contributions: Concept - S.K.; Design - S.K.; Supervision Y.E.Ü.; Resource - S.K.; Materials - I.K.; Data Collection\&/or Processing - H.T., R.E., E.G.Y.E.; Analysis\&/or Interpretation S.K.; Literature Search - S.K.; Writing - S.K.; Critical Reviews Y.E. $\ddot{U}$.

Conflict of Interest: No conflict of interest was declared by the authors.

Financial Disclosure: The authors declared that this study has received no financial support.

\section{References}

1. Watts DH, Krohn MA, Wener MH, Eschenbach DA. C-reactive protein in normal pregnancy. Obstet Gynecol 1991; 77:176-80. [CrossRef]

2. Kashanian M, Aghbali F, Mahali N. Evaluation of the diagnostic value of the first-trimester maternal serum high-sensitivity C-reactive protein level for prediction of pre-eclampsia. J Obstet Gynaecol Res 2013; 39: 1549-54. [CrossRef]

3. Rebelo F, Schlüssel MM, Vaz JS, Franco-Sena AB, Pinto TJ, Bastos FI, et al. C-reactive protein and later preeclampsia: systematic review and meta-analysis taking into account the weight status. $\mathrm{J}$ Hypertens 2013; 31: 16-26. [CrossRef]

4. Bakalis SP, Poon LC, Vayna AM, Pafilis I, Nicolaides KH. C-reactive protein at 11-13 weeks' gestation in spontaneous early preterm delivery. J Matern Fetal Neonatal Med 2012;25: 2475-8. [CrossRef]

5. Moghaddam Banaem L, Mohamadi B, Asghari Jaafarabadi M, Aliyan Moghadam N. Maternal serum C-reactive protein in early pregnancy and occurrence of preterm premature rupture of membranes and preterm birth. J Obstet Gynaecol Res 2012; 38: 780-6. [CrossRef]

6. Blasco LM. C-reactive protein levels in pregnancy. Environ Health Perspect 2012; 120:A342. [CrossRef]

7. Nielsen FR, Bek KM, Rasmussen PE, Qvist I, Tobiassen M. C-reactive protein during normal pregnancy. Eur J Obstet Gynecol Reprod Biol 1990; 35: 23-7. [CrossRef]

8. Wiser A, Sivan E, Dulitzki M, Chayen B, Schiff E, Bar-Chaim, A et al. $\mathrm{C}$-reactive protein and the mode of onset of labor in term pregnancies. Acta Obstet Gynecol Scand 2008; 87: 26-30. [CrossRef]

9. van de Laar R, van der Ham DP, Oei SG, Willekes C, Weiner CP, Mol BW. Accuracy of C-reactive protein determination in predicting chorioamnionitis and neonatal infection in pregnant women with premature rupture of membranes: a systematic review. Eur J Obstet Gynecol Reprod Biol 2009; 147: 124-9. [CrossRef]

10. Trochez-Martinez RD, Smith P, Lamont RF. Use of C-reactive protein as a predictor of chorioamnionitis in preterm prelabour rupture of membranes: a systematic review. BJOG 2007; 114: 796-801. [CrossRef]

11. Ozer KT, Kavak ZN, Gökaslan H, Elter K, Pekin T. Predictive power of maternal serum and amniotic fluid CRP and PAPP-A concentrations at the time of genetic amniocentesis for the preterm delivery. Eur J Obstet Gynecol Reprod Biol 2005; 122: 187-90. [CrossRef]

12. Ghezzi F, Franchi M, Raio L, Di Naro E, Bossi G, D'Eril GV, et al. Elevated amniotic fluid C-reactive protein at the time of genetic amniocentesis is a marker for preterm delivery. Am J Obstet Gynecol 2002;186: 268-73. [CrossRef]

13. Oh KJ, Park KH, Kim SN, Jeong EH, Lee SY, Yoon HY. Predictive value of intra-amniotic and serum markers for inflammatory lesions of preterm placenta. Placenta 2011; 32: 732-6. [CrossRef] 